\title{
Fabrication of Nanorattles with Passive Shell
}

Hao Ming Chen, ${ }^{1}$ Ru-Shi Liu, ${ }^{l^{*}}$ Kiyotaka Asakura, ${ }^{2}$ Jyh-Fu Lee, ${ }^{3}$ Ling-Yun Jang, ${ }^{3}$ and Shu-Fen Hu ${ }^{4}$

${ }^{1}$ Department of Chemistry, National Taiwan University, Taipei 106, Taiwan

${ }^{2}$ Catalysis Research Center, Hokkaido University, Sapporo, Japan,

${ }^{3}$ National Synchrotron Radiation Research Center, Hsinchu 300, Taiwan,

${ }^{4}$ National Nano Device Laboratories, Hsinchu 300, Taiwan

*Author to whom correspondence should be addressed; electronic mail: rsliu@ntu.edu.tw 
S1. Elemental analysis was performed on an ICP-AES.

\begin{tabular}{|c|c|c|}
\hline & As prepared nanorattles & Nanarattles after washing with $\mathrm{NH}_{4} \mathrm{OH}(\mathrm{aq})$ \\
\hline $25 \square$ & $\mathrm{Au} 54 \% ; \operatorname{Ag} 24 \% ; \mathrm{Cl} 22 \%$ & $\mathrm{Au} 91 \% ; \mathrm{Ag} 6 \% ; \mathrm{Cl} 3 \%$ \\
\hline $95 \square$ & $\mathrm{Au} 66 \% ; \operatorname{Ag} 25 \% ; \mathrm{Cl} 9 \%$ & $\mathrm{Au} 76 \% ; \operatorname{Ag} 22 \% ; \mathrm{Cl} 2 \%$ \\
\hline
\end{tabular}

* The nanorattles were washed with $\mathrm{NH} 4 \mathrm{OH}$ and centrifuged five times. 
S2. Best-fitted EXAFS Au L $\mathrm{L}_{3}$ edge spectra of Au nanoparticles, Au nanoparticles coating with Ag shell, nanorattles

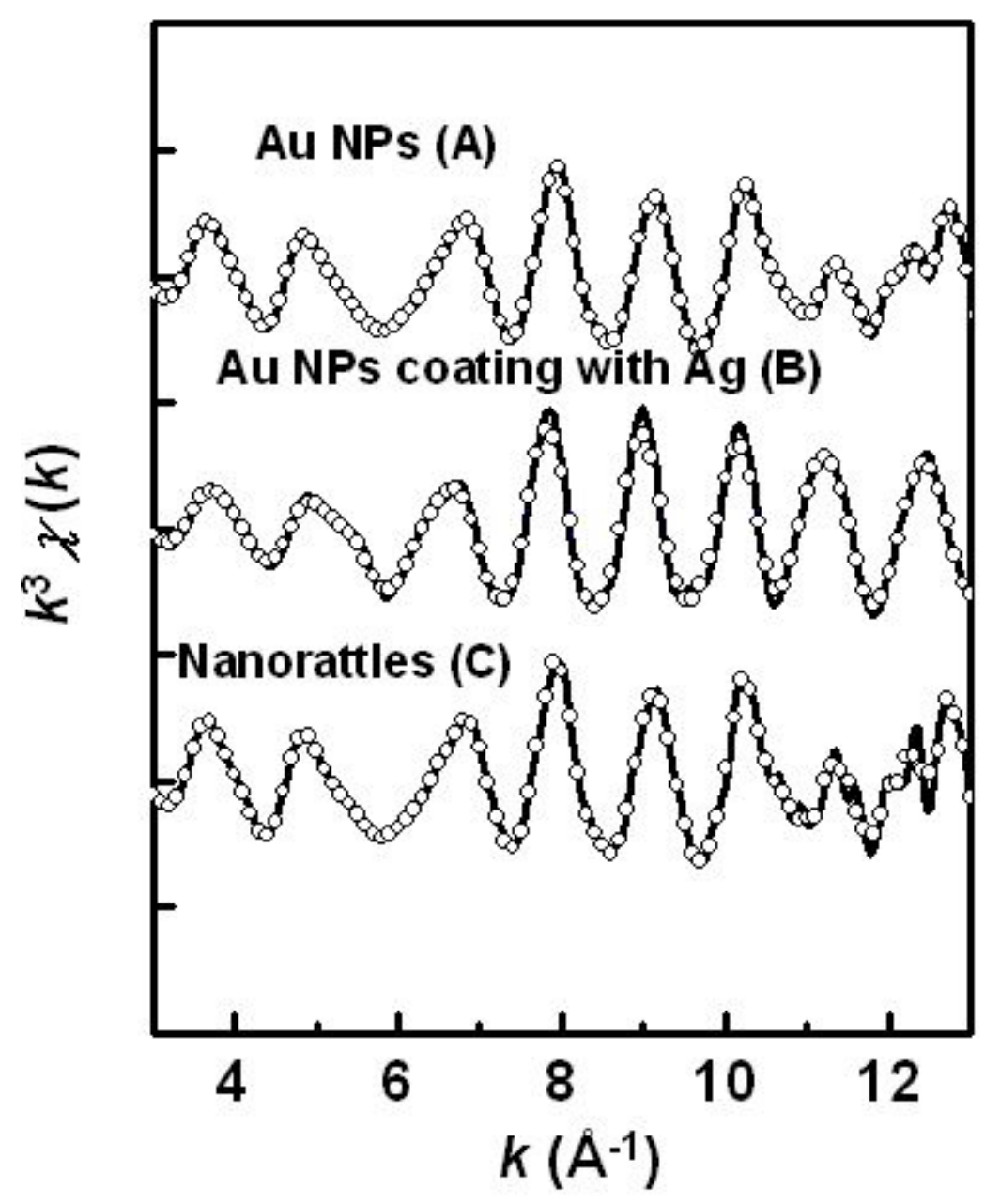


S3. Best-fitted EXAFS Ag K edge spectra of Au nanoparticles coating with Ag shell

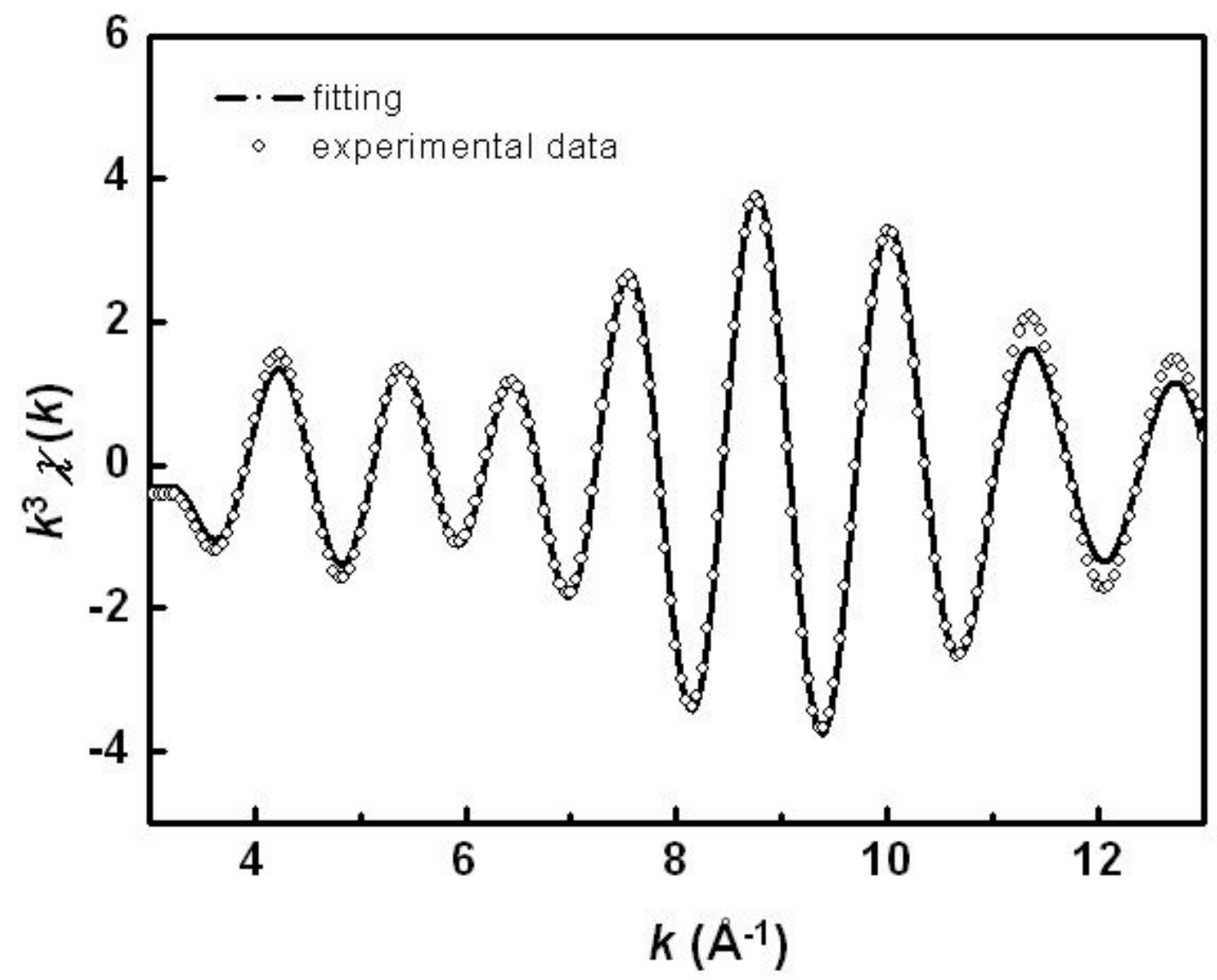

